\title{
A development index for the Greek regions
}

\author{
Panagiotis Artelaris ${ }^{1}$ (D)
}

Accepted: 24 May 2021 / Published online: 1 June 2021

(C) The Author(s), under exclusive licence to Springer Nature B.V. 2021

\begin{abstract}
There has been a growing consensus in recent years that development is a multidimensional concept that embodies the enhancement of several aspects of human life and, as a result, it is too complex to be captured by single indices. Composite Indicators have increasingly been recognised as useful tools in the measurement of this concept. In the absence of rigorous and comprehensive empirical studies in Greece on this topic, the paper assesses and reveals the developmental transformations of the regional economies at NUTS 2 and 3 levels in the period 1991-2011. In this way, this study provides a more comprehensive and integrative perspective of regional development in Greece presenting empirical evidence not only from a country with large and persistent regional inequalities but also from a cohesion country of the European Union for which regional policy has been of critical importance in the last decades. Moreover, the study adds to the literature shedding light on an under-researched topic; the importance of spatial heterogeneity in the construction of Composite Indicators. The results reveal a heterogeneous regional pattern of development for the Greek case. The findings can be used by policymakers as a way to better understand and improve the regional development process.
\end{abstract}

Keywords Human development · Well-being · Composite indicators · Regional rankings · Spatial heterogeneity $\cdot$ Benefit of doubt $(\mathrm{BoD})$

\section{Introduction}

One of the most important insights of recent studies is that development cannot be considered in strictly economic terms. Development is a multidimensional concept having also social, political and cultural dimensions and, as a result, it embodies the enhancement of several other aspects of human life. A number of geographers, regional scientists, economists and other social scientists have critiqued the exclusive focus on economic indicators and the traditional utilitarian notion of welfare and well-being, calling for a humanistic approach of development (Sen 1982; Dasgupta 2000; Dunford 2005; Hudson 2007; Pike et al. 2007; Stiglitz et al. 2009; Murias et al. 2012; Perrons 2012). The intensification of the discussion in the last 10 years has been strongly associated with the 2008 economic

Panagiotis Artelaris

partelar@hua.gr

1 Department of Geography, Harokopio University, Athens, Greece 
crisis (Boarini and D'ercole 2013; Artelaris 2017), while much more debate is expected in the years to come as a result of the effects of the COVID-19 pandemic.

The recognition of multidimensionality has given rise to increasing interest among policymakers, researchers, news agencies and the general public and a motivation for making more appropriate measurements. The "Istanbul Declaration" of 2007, affirmed by several important supranational organisations such as the Organisation for Economic Cooperation and Development (OECD), the European Commission (EC), the United Nations (UN) and the World Bank, and signed by many others, highlighted, for the first time, a broad international consensus on "the need to undertake the measurement of societal progress in every country, going beyond conventional economic measures such as GDP per capita" (OECD 2007). The "Beyond GDP" conference organised by the EC in 2007, the socalled Stiglitz-Sen-Fitoussi report (Stiglitz et al. 2009), and the OECD's global project on "Measuring the Progress of Societies" are also key milestones. The main conclusion drawn from this debate is not the complete rejection of Gross Domestic Product (GDP) as a measurement of development, but the need to measure human development according to a multidimensional view, where the economic dimension is considered together with other dimensions (Di Berardino et al. 2016). These initiatives called for new and improved approaches aimed at filling the gap in the measurement of human development.

The need for a multidimensional view of development has given rise to the field of Composite Indicators ${ }^{1}$ (also known as synthetic indices), which has grown significantly over the last decade and become much more rigorous and sophisticated (OECD 2008; Greco et al. 2019). The aim of a Composite Indicator (CI) is to measure multidimensional concepts without any reductionism (Munda 2015). In this sense, a CI combines many aspects of development, facilitating the reduction of the multifaceted reality to a single value. In recent years numerous CIs have been constructed and proposed by several national statistics institutes, non-government organisations (NGOs), think tanks, research centres and international and supranational organisations (such as the OECD, the UN, the EU and the World Economic Forum).

A common element of all these measurement efforts is that they focus on the national level, primarily because the available information at the sub-national (regional) level is scant. However, today, the most active and crucial area of research probably concerns the construction of CIs at the regional level, not only because of the increased availability and quality of regional data but also because of the need for better regional policies. It is difficult to get a complete picture of people's living conditions without considering the regional aspects of development (OECD 2015). In this context, several organisations such as the OECD and the EU have recently developed regional versions of their national CIs. Significant efforts to measure regional development have also been made by numerous scholars for individual countries (see for example Burchi and Gnesi 2015; Ferrara and Nisticò 2015; Calcagnini and Perugini 2019 for Italy; Marchante et al. 2006; Murias et al. 2016 for Spain; Silva and Ferreira-Lopes 2014 for Portugal; Wüst and Volkert 2012 for Germany).

For Greece, studies are scarce; Petrakos and Artelaris (2008), Liargovas and Fotopoulos (2009), Goletsis and Chletsos (2011), and Petrakos and Psycharis (2016) have constructed CIs for multidimensional views of development. However, the dimensions included in the CIs are not determined by a specific conceptual framework, and as a result, a coherent theoretical basis is absent. Moreover, the studies use annual data, and thus exclude from the

\footnotetext{
1 The need for measurement of several other multidimensional concepts such as competitiveness, globalisation, innovation and technology, has also given rise to the field of Composite Indicators.
} 
analysis some high-quality and more appropriate variables obtained by censuses, which are usually conducted once every 10 years. Finally, the lack of sensitivity analysis and neglect of spatial heterogeneity are some other limitations of these studies.

This paper therefore aims to provide a more comprehensive CI of development for the Greek regions. More specifically, the paper attempts to assess and reveal, using the human development and capability approach as a benchmark and exploiting the literature of CIs, the developmental transformations of the regional economies at Nomenclature of Territorial Units for Statistics (NUTS) 2 and 3 levels. To extend the period of analysis and increase reliability and comparability, the main data source for the construction of the CI is the census data provided by the Hellenic Statistical Authority (EL.STAT.) for the years 1991, 2001 and 2011. The dimensions of development are selected using the recent OECD framework as it includes not only the capabilities approach but also the more recent major theoretical developments. The results are also compared with the two most popular indicators of development, that is GDP per capita and the simple version of Human Development Index (HDI).

This study contributes to the literature presenting empirical evidence not only from a country with severe regional inequalities (OECD 2019; Artelaris 2021) and a distinct kind of spatial dualism in the form of Attiki (and its small near satellite regions) and non-Attiki but also from a cohesion country of the European Union (EU) for which regional development and policy have been of critical importance in the last four decades. Moreover, the study adds to the literature highlighting the importance of spatial heterogeneity in the construction of CIs; to achieve this, a recently developed technique, the spatial robust Benefit of the Doubt, is used. This method enables addressing for spatial heterogeneity introducing an additional constraint associated with spatial proximity (Fusco et. al. 2018).

The remainder of this paper is organised as follows. The next section shortly reviews the concept of development and its measurement while Sect. 3 presents the data and study area. Section 4 contains the methodology of the paper and Sect. 5 presents the empirical results. Finally, Sect. 6 concludes.

\section{2 (Regional) Development and its measurement: a short review of the literature}

\subsection{Conceptual framework}

There is an ongoing debate regarding the meaning of development and how to achieve it. This can be traced back, in the form of well-being, to ancient Greek ethical philosophy (see for instance the Epicurean and Aristotelian responses). In more recent years, there has also been debate concerning how to conceptualise and measure development. Development is a broad, complex, multifaceted and evolving concept embraced by various disciplines. Several other concepts have a similar meaning, such as human development, well-being, quality of life, (socio-economic) progress, living standards, life satisfaction, welfare, social welfare, happiness. These concepts are very similar because they focus on the living conditions of people in given spatial entities (Burchi and Gnesi 2015).

Although there is no clear consensus on a specific theoretical framework defining this concept, there are a number of theoretical strands. The most well-known, influential and probably most coherent multidimensional conceptualisation is the capabilities approach. Other significant strands include inter alia, the basic human values approach (Grisez et al. 
1987), the intermediate needs approach (Doyal and Gough 1993), the universal human values approach (Schwartz 1994), the domains of subjective well-being approach (Cummins 1996), the dimensions of well-being approach (Narayan et al. 2000) and the central human capabilities approach (Nussbaum 2000). ${ }^{2}$

The capabilities approach appeared as a reaction against mainstream positions in welfare economics and political philosophy and ethics, and has been considered not only as one of the main contenders in the field of different theories of social justice (Claassen 2016) but also as one of the most significant theoretical contributions to welfare analysis (Anand et al. 2005). One of its primary goals is to re-orient approaches to socio-economic development and public policy away from the concept of economic growth and GDP (Frediani et al. 2014), which cannot fully capture human progress. For economist Amartya Sen and philosopher Martha Nussbaum (Sen 1982, 1985 1993, 2004; Nussbaum 2000), who were the pioneers of the capabilities approach, based, more or less, on several thinkers such as Aristotle, Smith, Kant, Mill and Marx, development implies expanding the choices available to individuals, or their capabilities.

More specifically, this approach is based on two core concepts: functionings; and capabilities. The former is related to personal features: what a person is doing or achieving in their life (such as being literate or healthy). The latter is associated with what human beings can do or can achieve, that is, the range of options available to a person. In other words, capabilities concern the ability of an individual to achieve different combinations of functionings and, in this sense, expresses the real opportunities to achieve that status. Not surprisingly, Sen avoids a final specific and predetermined list of capabilities because to "insist on a fixed forever list of capabilities would deny the possibility of progress in social understanding and also go against the productive role of public discussion, social agitation, and open debates" (Sen 2004:80). In other words, the measurement reflects the values, norms and preferences of each society in a specific time frame.

\subsection{Measurement framework}

GDP is the most widely used measure of (regional) development. Although the ultimate goal of any society (and the objective of development policy) is to improve human (and not economic) development (UNDP 1990), its measurement has traditionally been limited to this indicator. Simplicity, both in terms of measurement and in terms of making comparisons among geographical units, is its most important advantage. GDP is also tangible and commonly understood. Moreover, it is used as the main eligibility criteria for EU funding and as the basic indicator of the effectiveness of EU regional policies.

However, although the weaknesses of GDP as a measure of development have long been considered (see for example Galbraith 1958; Samuelson 1961; Kuznets 1962; Nordhaus and Tobin 1973), it is now well established that GDP is an insufficient and poor measure of development (Sen 1982; Dasgupta 2000; OECD 2007; Stiglitz et al. 2009). An increase in GDP does not mean an increase in development since GDP captures only one of its dimensions. GDP focuses on the commodities produced rather than on those elements shaping the enjoyment and "utility" that people derive from consumption such as education, health and personal security, and excludes a range of non-market activities that influence human development such as leisure. As Stiglitz et al. (2009:85) state, "Too

${ }^{2}$ For a review see also McGillivray (2007:4). 
much emphasis on GDP as the unique benchmark can lead to misleading indications about how well-off people are and run the risk of leading to the wrong policy decisions". In other words, income is a means, not an end; the end goal of development must be human well-being (UNDP 1990:10). Another line of criticism centres on GDP's precision. For instance, GDP excludes the services produced by households for people's own use, it does not take into account the externalities and distribution of income, and neglects the underground economy (Sen 1985; Perrons 2012; Boarini and D'ercole 2013). Moreover, it does not accurately measure the local income because a part of the income may be consumed in other or foreign areas. ${ }^{3}$

In light of such criticism, there has been a growing interest in alternative methods of measuring. As mentioned above, the most common approach is based on the use of CIs. In this way, a wide array of developmental aspects can be incorporated into an indicator. In general terms, CIs should: (a) be grounded in a well-established theory; (b) have a public policy purpose; (c) be based on time series data to allow periodic monitoring and control (Hagerty et al. 2001). Since there is no clear consensus on a specific theoretical framework defining development, there is no consensus on its measurement. Moreover, in most of the theoretical strands, such as the capabilities approach, there is not a specific and predetermined list of developmental dimensions. What type of dimensions is best is the subject of considerable debate and controversy; the list is extremely diverse, covering various aspects of development.

The Human Development Index (HDI), introduced by the UN in 1990 (UNDP 1990), is one of the oldest and most significant attempts to overcome the narrow focus of GDP. ${ }^{4}$ The HDI, rooted in the capability approach, has gained noteworthy prominence through the years, becoming a tool for evaluating and monitoring development in international policy discussion. Sen was initially sceptical about the ability of the indicator to capture the complexity of the human capabilities approach. However, in later years he was convinced that this indicator was able to provide clarity about the social aspects of human development as well as to attract political attention (Sen 1999:23). The calculation of the index involves three dimensions: long and healthy life (assessed by life expectancy at birth); knowledge (measured by mean and expected years of schooling); and a decent standard of living (represented by income). Although the index has been successfully used as an alternative to GDP to evaluate human development, it has been criticised on different grounds (see Raworth and Stewart 2005; Alkire 2010; Reig-Martınez 2013). One significant source of criticism centres on the restrictive set of dimensions representing a very narrow and limited perspective of development.

More recently, considerable efforts have been made to improve this indicator by broadening the concept of human development (Booysen 2002; Calcagnini and Perugini 2019). Among the most recent developments is the Better Life Index introduced by the OECD (OECD 2011). This framework, drawing upon the recommendations of a large body of

\footnotetext{
3 In Greece, this problem is significant because its largest regions, Attiki and Thessaloniki, export a large part of their economic activity to their neighbouring satellite regions and many employees commute to work on a daily basis (Petrakos and Artelaris 2008). The considerable and frequent changes and revisions of the regional GDP from the Hellenic Statistical Authority (ELSTAT) (Papadaskalopoulos and Christofakis 2008; Petrakos and Psycharis 2016; Artelaris and Tsirbas 2018) reinforce the inappropriateness of this indicator.

${ }^{4}$ Other popular CIs include the Happy Planet Index (HPI), the Genuine Progress Indicator (GPI) and Gross Environmental Sustainable Development Index (GESDI) (see Hagerty et al. 2001; Barrington-Leigh and Escande 2017; Strezov et al. 2017) for reviews of composite indicators).
} 
literature (e.g., Sen 1998; Stiglitz et al. 2009; Nussbaum 2011), attempts to operationalise the capabilities approach:"operationalizing the framework means first, selecting a list of basic and universal functionings and capabilities; and, second, identifying the specific indicators measuring each of them" (OECD 2013:22). The regional version of the index comprises nine dimensions which can be broadly categorised as material living conditions (housing, income, and jobs), and quality of life (health, education, environment, civic engagement, safety, and accessibility of services). As is evident, the indicator recalls the basic aspects of the HDI including several significant recent initiatives for a different and more holistic measurement of development.

\section{Variables, measurement and data}

In this study, the dimensions of development were selected by following the OECD framework for two primary reasons. First, from a normative perspective, it includes not only the capabilities approach (Durand 2015) but also the more recent major theoretical developments (e.g., Stiglitz-Sen-Fitoussi report). Second, as the index is estimated mainly for OECD spatial units, it takes into account the higher level of development of Greek regions.

Data selection is a fundamental step in the process of construction of a CI because it is strongly related to the quality of the index. Although ample data is typically available at the national level, there are severe constraints at the regional level since data is scarce and there is a lack of data covering significant time periods. The selection of the variables included in this study was based on several criteria. First, based on theoretical considerations, each variable represents at least one aspect of development. Second, data should be available in the future so as to provide a tool for future comparisons. Third, to facilitate comparisons, data should be available at both main geographical scales (i.e., NUTS 2 and 3). ${ }^{5}$ Fourth, to facilitate long-term analysis, data should be available for at least 20 years. Fifth, data is only obtained from credible sources.

Based on the above, a range of 10 variables was selected representing eight critical dimensions of development. Table 1 provides an overview of these variables; the table presents the selected dimensions variables and indicators entered into the calculation of the CI as well as the measurement unit, the source of data and the justification for the inclusion. The main data source of the variables is the census data provided by the Hellenic Statistical Authority (EL.STAT.) for the years 1991, 2001 and 2011. We, however, complemented those data by adding further data from three other sources: The Ministry of Interior (elections data), the Laboratory of Demographic and Social Analyses of the University of Thessaly (data for the variable of life expectancy), and ARDECO, the Annual Regional Database of the European Commission's Directorate-General for Regional and Urban Policy (regional GDP).

Compared to the Better Life Index, two changes were made. First, the dimensions of environmental quality, personal safety and accessibility of services were not included because of the lack of relevant statistical information. On the other hand, the dimension of work-life balance, available in the national but not at the regional version of the Better Life Index, was included in our CI. Second, gender inequality was added in the CI; this is

\footnotetext{
5 The main territorial structure in Greece includes 13 regions (periferia) corresponding to NUTS 2 level of the Eurostat and 51 regions (prefectures/nomos) corresponding to NUTS 3 level. Since 2011, 74 regional units have replaced the 51 prefectures with the Kallikratis reform.
} 


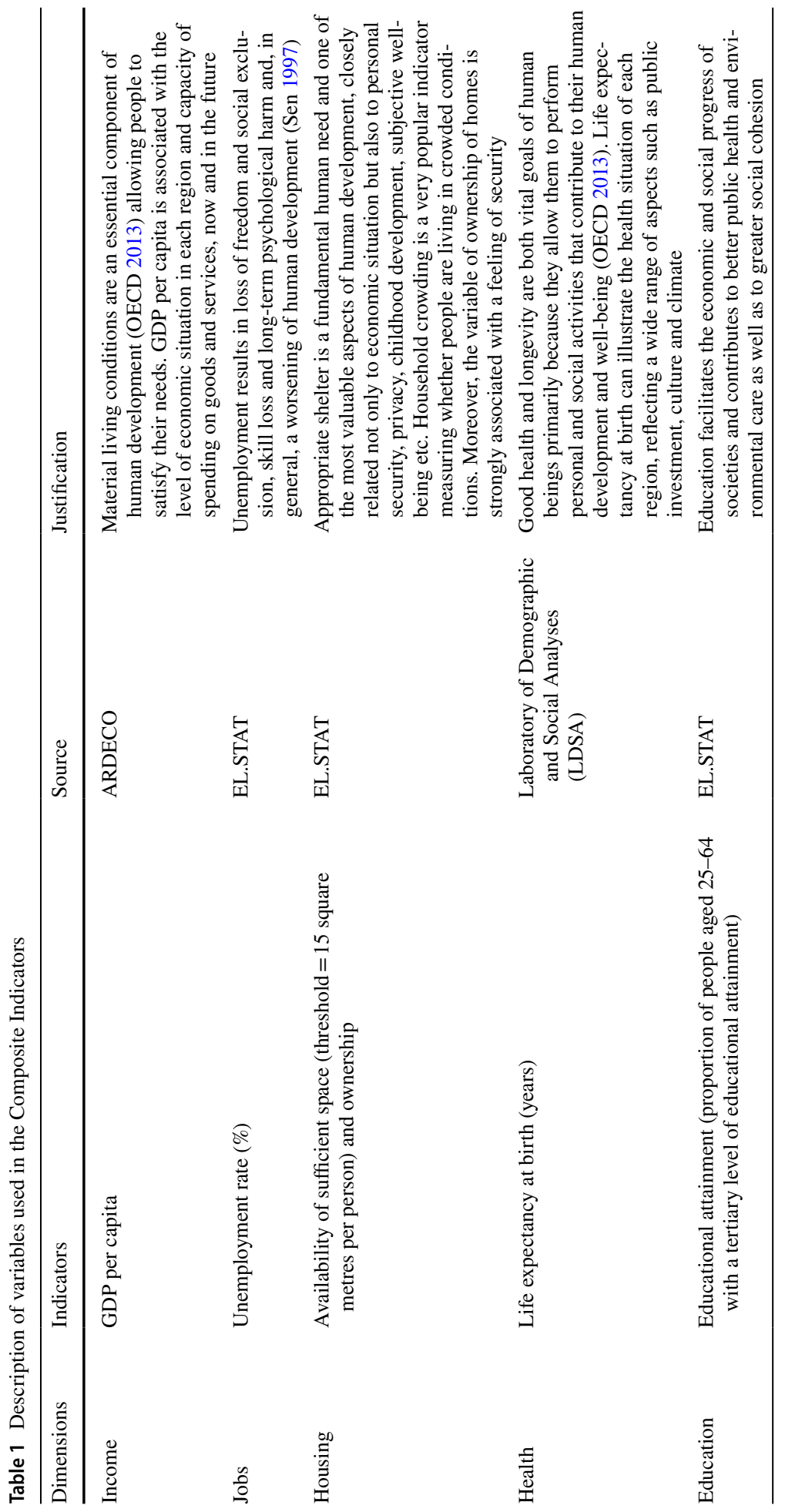




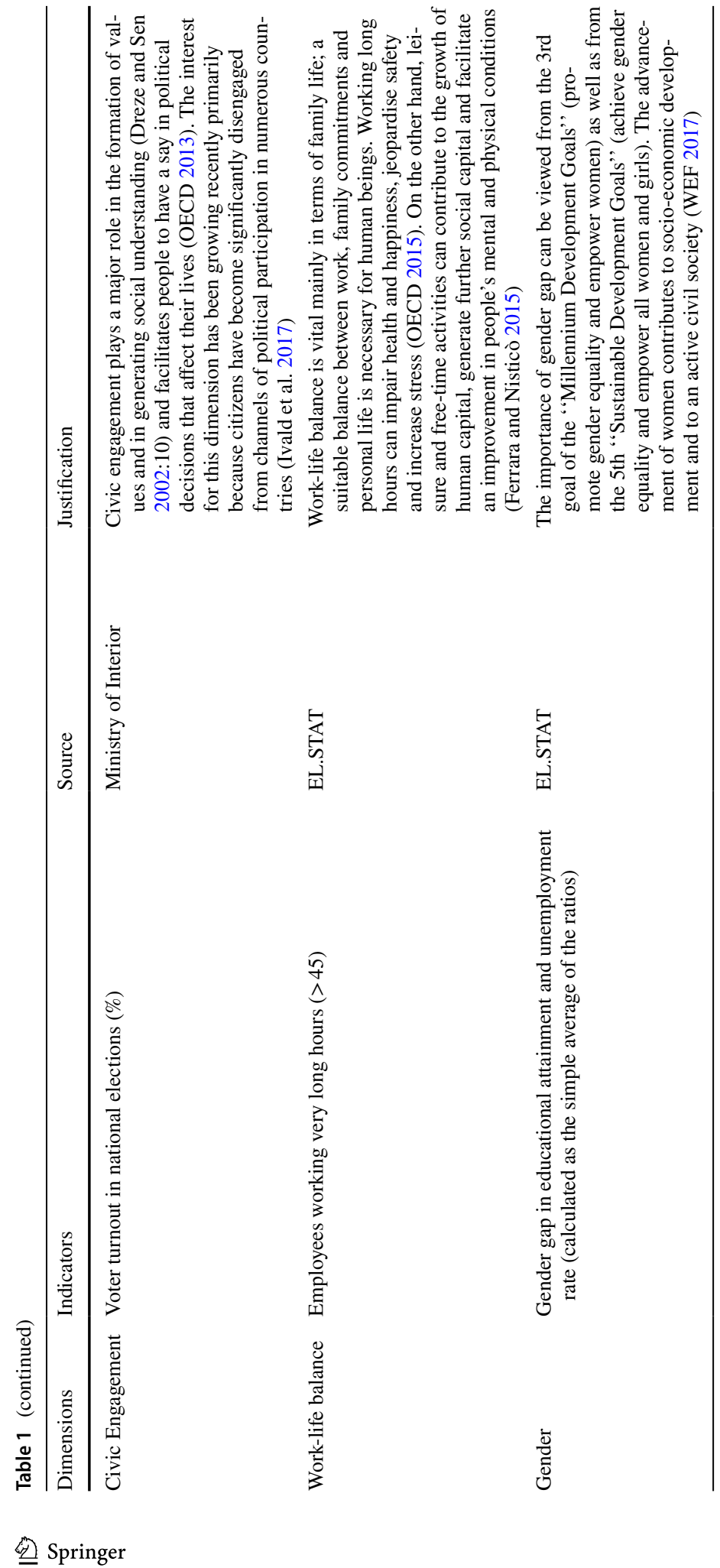


an important dimension of development frequently not included in similar indicators but viewed both from the 3rd goal of the "Millennium Development Goals" and from the 5th "Sustainable Development Goals'.

\section{Constructing the composite indicator}

As mentioned above, the most common and practical way to measure development is through the CIs. These indicators, although they are not without critics (Dialga and Giang 2017), are considered standard and effective tools for the measurement of multidimensional phenomena. A CI is the mathematical combination of individual indicators that represent different dimensions of a concept whose description is the objective of the analysis (see Saisana and Tarantola 2002; OECD 2008).

Although there has been a proliferation in the use of CIs over recent years, there is no commonly accepted methodology for building them (Booysen 2002; Freudenberg 2003; Saltelli 2007; Kuc-Czarnecka et al. 2020). Typically, the synthesis of indicators involves two main distinct steps and each step requires a careful and comprehensive investigation to avoid producing results of dubious analytic rigor (Saisana and Saltelli 2008). The key steps include normalisation and aggregation-weighting phases. However, before these steps, the "direction" of each indicator has to be defined since only indicators with the same direction should be aggregated. In this study, the direction of the indicator has been assumed to be positive for all indicators, that is, the higher the score the more developed the region.

The normalisation technique is necessary for removing the scale effect of a CI because the selected variables are not normally measured in the same units (OECD 2008). The values should therefore be normalised to have the same range, making it possible to aggregate them into a CI. Several standardisation techniques have been suggested in the literature (OECD 2008). The most common techniques are based either on re-scaled values with a fixed range but with different mean and standard deviation (known as min-max method), or on standardised values with fixed mean and standard deviation but different ranges (known as z-score). In the initial version of the CI, we applied the former technique.

The most important and highly debated step concerns the selection of aggregation and weighting methods. This step is related to the criteria applied to assign weights to the single indicators and the mathematical function used by which the whole set of indicators is synthesised into a unique value. Although the selection of techniques can have a significant impact on the results and rankings of the analysis, there is no agreed methodology and consensus on how to determine the appropriate weighting and aggregation scheme (OECD 2008).

Typically, weights are selected on the basis of the theory and concept analysed and the value judgments and common sense (normative approach). In most of the cases, equal weighting is adopted to avoid subjective choices easily open to criticism; however, it is worth noting that this does not mean "no weights", but implicitly suggests that the weights are equal. In the more recent years, the most common approach is to derive weights using statistical techniques such as Factor Analysis and Data Envelopment Analysis (data-driven approach). Such a data-oriented method is strongly motivated by the lack of consensus on an appropriate weighting scheme. The distinction between the two approaches i.e. 
normative and data-driven reflects the philosophical is-ought problem, as articulated by David Hume in the eighteenth century (Decancq and Ana Lugo 2013). ${ }^{6}$

As far as aggregation choices are concerned, the most frequently used are linear and geometric (OECD 2008). The former, which averages the normalised individual indicators, does not make strong assumptions about the relationships between variables, compared to geometric aggregation (Oţoiu and Grădinaru 2018) and assumes a full compensability among the different components (Krishnan 2015). This means that poor performance in one indicator can be fully compensated by good performance in another indicator. The latter, i.e. geometric aggregation involves aggregation by the geometric mean and is the most common technique to obtain not compensated indicators (Sarra and Nissi 2019).

In this study, we calculate weights using the Benefit of Doubt (BoD) model $^{7}$ based on Data Envelopment Analysis (DEA). This is a common method in the CI literature that can generate endogenous weights according to an optimization process (Cherchye et al. 2007; OECD 2008); the weights are chosen to maximize the value of the composite indicator for each region separately (Grupp and Schubert 2010). In other words, the estimated weights are region-specific implying that they differ among regions. An advantage of this method, as any other method based on a "pure" statistical technique, is the reduction of subjectivity because weights are data-driven rather than they are assigned by the researcher (Cartone and Postiglione 2020). This method is typically employed with linear aggregation (Hoskins and Mascherini 2009).

However, regions commonly differ in several aspects implying the presence of spatial heterogeneity. Most of the CI literature has neglected this problem producing invalid, inaccurate and biased results (Fusco et al. 2018). In the recent few years, a handful of studies have raised this issue developing methods to properly address spatial heterogeneity in the estimation of CI scores (Papalia and Ciavolino 2015; Fusco et. al. 2018; Sarra and Nissi 2019; Walheer 2019; Cartone and Panzera 2020; Cartone and Postiglione 2020; Casolani et al. 2020). As a result, in this study, we use the spatial robust Benefit of the Doubt technique that enables addressing for spatial heterogeneity in the construction of CIs, introducing an additional constraint associated with spatial proximity (Fusco et al. 2018). ${ }^{8}$ In parallel, the results of this method are less sensitive to extreme values and outliers because it controls the influences of the observations in the data.

\section{Empirical results}

This section presents the results of the CI for the Greek regions in the period 1991-2011. The first sub-section reports the performance of NUTS 2 while the second presents the performance of NUTS 3 regions. The last sub-section discusses the strategy of sensitivity analysis employed in the study.

\footnotetext{
6 David Hume states that many claims about what "ought to be" are based on statements about "what is".

7 However, for theoretical reasons, we allocate weights of $1 / 2$ to dimensions that belong to each sub-indicator (i.e., gender and housing).

${ }^{8}$ In this study, the spatial robust Benefit of the Doubt has been computed using the 'Compind' $R$ package (Vidoli and Fusco 2019).
} 
Table 2 Composite indicator of development, Rankings, HDI and per capita GDP in the regions of Greece, NUTS 2, 1991-2011

\begin{tabular}{|c|c|c|c|c|c|c|c|c|c|c|}
\hline \multirow[t]{2}{*}{ Regions } & \multicolumn{4}{|l|}{ CI } & \multicolumn{3}{|l|}{ HDI } & \multicolumn{3}{|c|}{ per capita GDP } \\
\hline & 1991 & & 2001 & 2011 & 1991 & 2001 & 2011 & 1991 & 2001 & 2011 \\
\hline Eastern Macedonia, Thrace & 12 & 11 & & 7 & 8 & 10 & 13 & 7 & 13 & 11 \\
\hline Central Macedonia & 8 & 6 & & 1 & 5 & 4 & 7 & 9 & 7 & 7 \\
\hline Western Macedonia & 10 & 10 & & 6 & 12 & 12 & 12 & 5 & 9 & 3 \\
\hline Epirus & 2 & 5 & & 3 & 13 & 9 & 5 & 13 & 11 & 12 \\
\hline Thessaly & 4 & 2 & & 4 & 9 & 8 & 6 & 11 & 10 & 9 \\
\hline Ionian Islands & 13 & 8 & & 10 & 4 & 11 & 9 & 3 & 4 & 8 \\
\hline Western Greece & 7 & 7 & & 5 & 11 & 13 & 11 & 10 & 12 & 13 \\
\hline Central Greece & 11 & 13 & & 11 & 6 & 2 & 10 & 2 & 3 & 5 \\
\hline Attiki & 1 & 1 & & 2 & 1 & 1 & 1 & 4 & 2 & 1 \\
\hline Peloponnese & 9 & 12 & & 12 & 7 & 6 & 8 & 8 & 6 & 10 \\
\hline North Aegean & 6 & 4 & & 9 & 10 & 5 & 3 & 12 & 8 & 6 \\
\hline South Aegean & 3 & 9 & & 13 & 2 & 7 & 2 & 1 & 1 & 2 \\
\hline Crete & 5 & 3 & & 8 & 3 & 3 & 4 & 6 & 5 & 4 \\
\hline
\end{tabular}

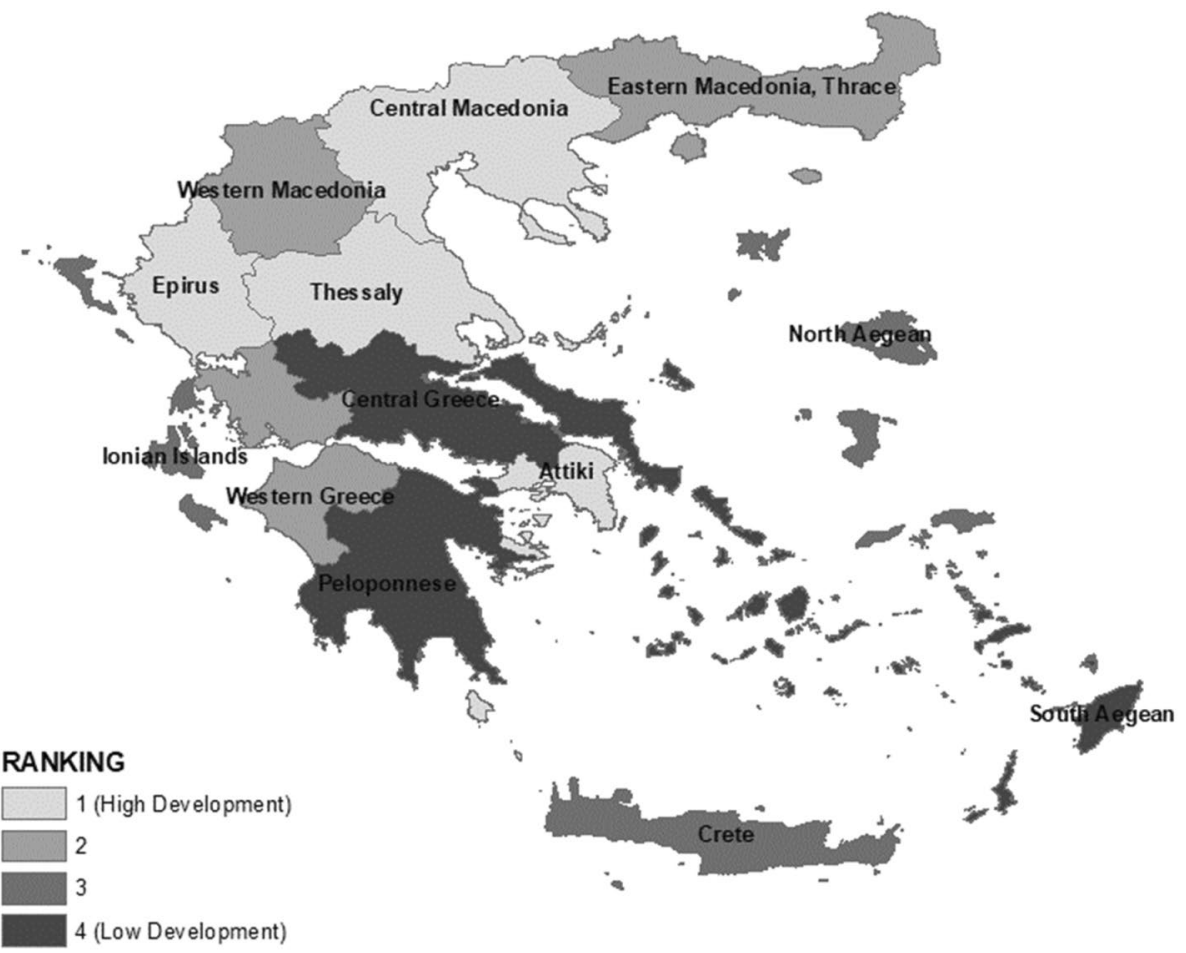

Fig. 1 Regional rankings of CI in quantiles in Greece, NUTS 2, 2011. Source: Authors calculations 


\subsection{NUTS 2 regions}

The CI rankings of the regions at NUTS 2 level are depicted in the first columns of Table 2 for the years 1991, 2001 and 2011 while Fig. 1 shows the rankings on a map for 2011 (ranking in quantiles). The same table also presents the rankings of the two most common alternative indicators, that is HDI and GDP per capita, to highlight the differences. A higher ranking in CIs means a better performance. The most developed regions for 2011 were Central Macedonia, Attiki, Epirus, and Thessaly, while the least developed ones were the South Aegean, Peloponnese, Central Greece and the Ionian Islands.

More specifically, Central Macedonia, the second most populous and urbanized region of the country, with approximately $17 \%$ of the national population and GDP, was the most developed region regarding CI for 2011. It gained several positions since 1991 presenting one of the most remarkable improvements in terms of ranking. It hosts not only the second most populous and important economic, commercial and cultural center in Greece (i.e., Thessaloniki), but also several other considerable urban agglomerations (e.g., Serres, Katerini, Veroia, Kilkis); it primarily specialises in manufacturing and partly in financial and insurance activities and real estate. Interestingly, when the other two alternative indicators are used, its performance is worse for 2011. Attiki was the second most developed region in Greece in 2011, and the most developed in 1991 and 2001. It is the main economic, commercial and cultural centre, contributing about $50 \%$ of the national GDP and $40 \%$ of the total population of the country. It is the most urbanized region of Greece and is a highly specialised region in the tertiary sector, mainly in financial and insurance activities. Attiki also scores high in the other two alternative indicators examined. Surprisingly, the third most developed region in 2011 (and 5th in terms of HDI) was Epirus, one of the least developed regions of the country in terms of per capita GDP. Epirus is a mountainous region in the far north-western corner of mainland Greece on the border with Albania and one of the most sparsely populated regions. It has only one significant city, Ioannina (the seventh most populous city in Greece), three other medium-sized cities (Arta, Preveza and Igoumenitsa), low population density and is specialised in agriculture. Thessaly, the third largest region in terms of population, was the fourth most developed region in the country in 2011. It is also the third most urbanized region of the country hosting the 5th and 6th most populous cities in the country (i.e., Larissa and Volos) and is specialised in agriculture and manufacturing. Interestingly, it occupied relatively low positions for the other years and indicators examined, especially in terms of per capita GDP.

On the other hand, the least developed region in 2011, regarding the CI, was the South Aegean. It is a less populous region consisting only of island areas and is highly specialised in tourism. Interestingly, it lost several positions in the rankings since 1991 due to inferior performance in several sub-indicators (mainly education and housing). Paradoxically, this is one of the most developed regions in Greece concerning the other indicators examined. Peloponnese was the 2nd least developed region of the country in 2011 and hosts only one (middle-size) city (i.e. Kalamata). Its economic structure is highly dependent on the primary sector and especially agriculture, and occupies one of the lowest positions in the tertiary sector, especially in the financial sector. It was also the region with the fourth-lowest GDP per capita in the country in 2011. Interestingly, it presented average performance scores for all years of the analysis and indicators examined (although its rank deteriorated in the period 1991-2001). The region of Central Greece, located in the central part of mainland Greece, is the 3rd least developed region for 2011. It is the eighth-most populated and urbanized region of Greece. It specialises primarily in manufacturing (and 


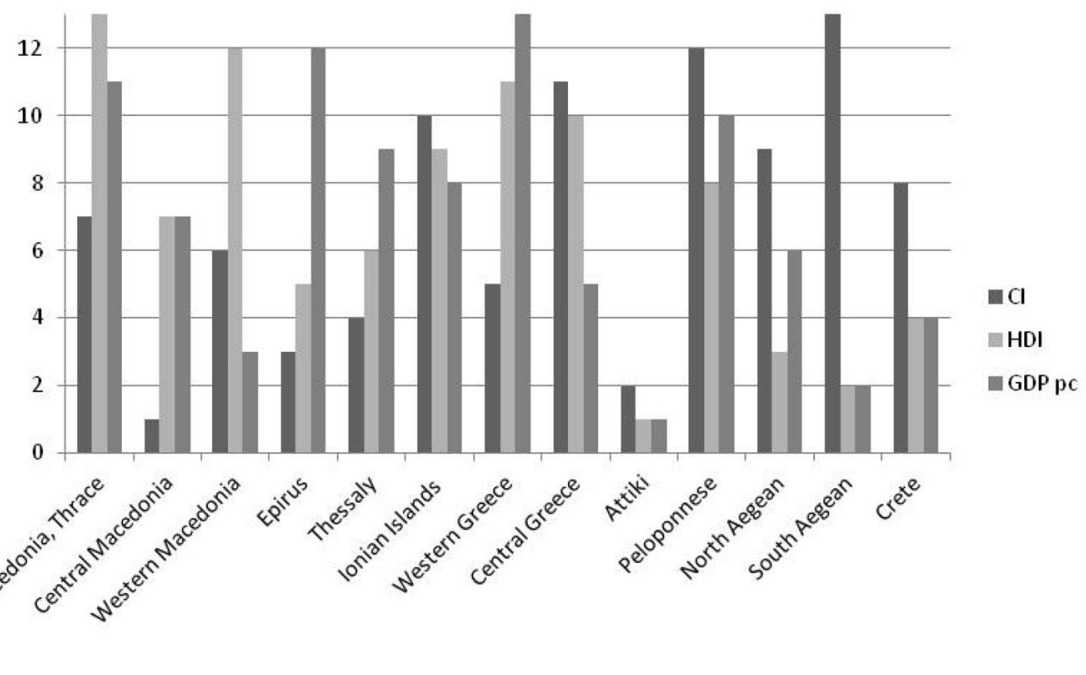

Fig. 2 Rankings for composite indicator (CI), HDI (Human Development Index) and GDP per capita, NUTS 2 region. Note: A lower ranking means a better performance. Source: Authors calculations

agriculture) and has one of the lowest shares in GDP and employment in the tertiary sector. The better performance of the region in terms of GDP is explained by the fact that Attiki "export" a large part of its economic activity to this neighbouring satellite region and many employees commute to work on a daily basis. The Ionian Islands, the fourth least developed region, is located in the western part of Greece and has no land borders. It is the second least populous region of the country and a significant tourism destination without significant urban agglomerations. Interestingly, when the other two alternative indicators are used, its performance is similar.

Based on the above discussion, one might assume that there is only a moderate (for HDI) or weak (for GDP per capita) correlation between the CI and the rest of the indicators examined. To better articulate this point, Fig. 2 compares the rankings obtained using the three indicators for the year 2011 to highlight the differences and similarities. The rankings are dissimilar for several cases and there are some cases with extremely large differences. For example, while Ipeiros in 2011 occupied the third position in terms of CI, it occupied the fifth position in terms of HDI and the 12th position in terms of GDP per capita. Moreover, while South Aegean for the same year occupied the 13th position in terms of CI, it occupied the second position in terms of HDI and GDP per capita. These differences shed light on the restrictive set of dimensions captured by HDI and GDP per capita. On the other hand, there are some regions, such as Attiki and Ionian Islands, occupying more similar positions regarding the three indicators.

Table 3 compares the regional rankings of our CI with the rankings obtained by the previous similar studies for the (common) year 2000/01. There are significant similarities and differences between the rankings among the different CIs. The most striking difference between our CI and the others is observed in South Aegean, while the most notable similarity is observed in Eastern Macedonia and Thrace, Attiki and Peloponnese. The differences among rankings can be explained by the different indicators and weighting schemes used. 
Table 3 Ranking comparison of different indicators in the regions of Greece, NUTS 2, (year 2000 or 2001)

\begin{tabular}{lcccc}
\hline Regions & Our CI & $\begin{array}{l}\text { Petrakos and } \\
\text { Psycharis }\end{array}$ & $\begin{array}{l}\text { Goletsis and } \\
\text { Chletsos }\end{array}$ & $\begin{array}{l}\text { Liargovas } \\
\text { and Foto- } \\
\text { poulos }\end{array}$ \\
\hline Eastern Macedonia, Thrace & 7 & 9 & 8 & 7 \\
Central Macedonia & 1 & 3 & 5 & 5 \\
Western Macedonia & 6 & 11 & 9 & 11 \\
Epirus & 3 & 12 & 6 & 13 \\
Thessaly & 4 & 7 & 10 & 6 \\
Ionian Islands & 10 & 6 & 3 & 2 \\
Western Greece & 5 & 13 & 11 & 10 \\
Central Greece & 11 & 8 & 13 & 8 \\
Attiki & 2 & 1 & 4 & 1 \\
Peloponnese & 12 & 10 & 7 & 12 \\
North Aegean & 9 & 5 & 1 & 4 \\
South Aegean & 13 & 2 & 2 & 3 \\
Crete & 8 & 4 & & \\
\hline
\end{tabular}

CI

\subsection{NUTS 3 regions}

The CI rankings of the regions at NUTS 3 level are presented in the first columns of Table 4 for all years of the analysis while Fig. 3 shows the rankings on a map (ranking in quantiles). The 10 most developed regions for 2011 are Thessaloniki, Ioannina, Attiki, Lefkada, Kozani, Kavala, Magnisia, Larisa, Achaia and Chania. Attiki and Thessaloniki are the two most important urban agglomerations of the country, Lefkada is an island in the Ionian Sea connected to mainland Greece with a bridge, Kozani is a significant industrial centre, while the rest of the regions include some of the most important urban agglomerations of the country. Interestingly, some of these regions present low levels of per capita GDP for the same year (that is, 2011). For instance, Ioannina occupies the 33rd, Thessaloniki occupies the 15 th, while Larisa occupies the 25 th position. The differences between the CI and HDI are considerable but not very large except for Kozani and Kavala, which occupies the 28th and 27th position in the ranking of the HDI respectively.

On the other hand, the 10 least developed NUTS 3 regions of the country for 2011, regarding the CI, are Ileia, Voiotia, Zakynthos, Pella, Aitoloakarnania, Chalkidiki, Evrytania, Rodopi, Kilkis and Lakonia. Common features among them are small population size and the absence of significant urban agglomerations, while most of them are either border regions, especially in the north of the country, or neighbouring satellite areas of Attiki and Thessaloniki. Interestingly, some of these regions present relatively high levels of per capita GDP; for instance, Voiotia occupies the 3rd position, ${ }^{9}$ Zakynthos occupies the 4th position and Chalkidiki occupies the 16th position in the ranking list. The differences between the CI and HDI are significant for a few cases since, for example, Lakonia occupies the

\footnotetext{
${ }^{9}$ Keep in mind that the better performance of the region in terms of GDP is explained by the fact that Attiki "export" a large part of its economic activity to this neighbouring satellite region.
} 
Table 4 Composite indicator of development, Rankings, HDI and per capita GDP in the regions of Greece, NUTS 3, 1991-2011

\begin{tabular}{|c|c|c|c|c|c|c|c|c|c|}
\hline \multirow[t]{2}{*}{ Regions } & \multicolumn{3}{|l|}{$\mathrm{CI}$} & \multicolumn{3}{|l|}{ HDI } & \multicolumn{3}{|c|}{ Per capita GDP } \\
\hline & 1991 & 2001 & 2011 & 1991 & 2001 & 2011 & 1991 & 2001 & 2011 \\
\hline Evros & 19 & 7 & 12 & 15 & 12 & 20 & 14 & 34 & 29 \\
\hline Xanthi & 40 & 16 & 36 & 33 & 40 & 50 & 21 & 36 & 28 \\
\hline Rodopi & 49 & 35 & 44 & 22 & 28 & 33 & 30 & 35 & 32 \\
\hline Drama & 33 & 30 & 32 & 38 & 49 & 47 & 16 & 45 & 49 \\
\hline Kavala & 11 & 4 & 6 & 24 & 29 & 27 & 19 & 44 & 18 \\
\hline Imathia & 26 & 29 & 31 & 31 & 33 & 43 & 7 & 22 & 39 \\
\hline Thessaloniki & 1 & 1 & 1 & 5 & 2 & 12 & 35 & 10 & 15 \\
\hline Kilkis & 47 & 41 & 43 & 17 & 44 & 45 & 9 & 27 & 36 \\
\hline Pella & 48 & 50 & 48 & 39 & 42 & 41 & 31 & 40 & 40 \\
\hline Pieria & 27 & 28 & 27 & 23 & 22 & 38 & 27 & 37 & 38 \\
\hline Serres & 43 & 36 & 38 & 30 & 47 & 44 & 36 & 50 & 51 \\
\hline Chalkidiki & 46 & 47 & 46 & 32 & 37 & 34 & 42 & 32 & 16 \\
\hline Grevena & 28 & 33 & 29 & 51 & 43 & 40 & 43 & 42 & 46 \\
\hline Kastoria & 34 & 37 & 33 & 48 & 51 & 49 & 26 & 24 & 47 \\
\hline Kozani & 21 & 23 & 5 & 45 & 36 & 28 & 8 & 15 & 6 \\
\hline Florina & 10 & 22 & 17 & 47 & 30 & 26 & 37 & 38 & 7 \\
\hline Karditsa & 42 & 44 & 35 & 37 & 48 & 42 & 46 & 49 & 48 \\
\hline Larisa & 14 & 6 & 8 & 14 & 8 & 18 & 34 & 18 & 25 \\
\hline Magnisia & 6 & 10 & 7 & 16 & 11 & 13 & 24 & 13 & 9 \\
\hline Trikala & 24 & 24 & 14 & 36 & 24 & 35 & 41 & 48 & 44 \\
\hline Arta & 32 & 26 & 15 & 49 & 39 & 39 & 51 & 46 & 42 \\
\hline Thesprotia & 44 & 40 & 39 & 42 & 34 & 36 & 23 & 21 & 27 \\
\hline Ioannina & 3 & 2 & 2 & 40 & 6 & 10 & 48 & 26 & 33 \\
\hline Preveza & 8 & 19 & 21 & 25 & 27 & 30 & 17 & 23 & 35 \\
\hline Zakynthos & 41 & 45 & 49 & 34 & 38 & 19 & 28 & 4 & 4 \\
\hline Kerkyra & 23 & 31 & 34 & 12 & 45 & 37 & 10 & 17 & 37 \\
\hline Kefallinia & 20 & 14 & 16 & 10 & 20 & 4 & 4 & 12 & 5 \\
\hline Lefkada & 13 & 18 & 4 & 26 & 14 & 14 & 44 & 30 & 23 \\
\hline Aitoloakarnania & 38 & 42 & 47 & 46 & 46 & 46 & 45 & 43 & 41 \\
\hline Achaia & 9 & 17 & 9 & 20 & 21 & 24 & 18 & 19 & 24 \\
\hline Ileia & 51 & 51 & 51 & 43 & 50 & 48 & 33 & 51 & 50 \\
\hline Voiotia & 39 & 48 & 50 & 4 & 3 & 15 & 1 & 1 & 3 \\
\hline Evvoia & 30 & 32 & 28 & 44 & 26 & 29 & 39 & 25 & 19 \\
\hline Evrytania & 50 & 46 & 45 & 50 & 41 & 51 & 20 & 39 & 45 \\
\hline Fthiotida & 22 & 21 & 25 & 19 & 19 & 31 & 13 & 16 & 31 \\
\hline Fokida & 29 & 25 & 18 & 41 & 31 & 32 & 29 & 33 & 34 \\
\hline Argolida & 35 & 39 & 41 & 18 & 25 & 22 & 40 & 29 & 22 \\
\hline Arkadia & 17 & 12 & 24 & 13 & 9 & 16 & 11 & 7 & 12 \\
\hline Korinthia & 25 & 38 & 30 & 8 & 4 & 21 & 3 & 2 & 14 \\
\hline Lakonia & 45 & 49 & 42 & 21 & 23 & 23 & 47 & 41 & 43 \\
\hline Messinia & 31 & 34 & 26 & 35 & 35 & 25 & 49 & 47 & 30 \\
\hline Attiki & 2 & 3 & 3 & 1 & 1 & 1 & 12 & 5 & 2 \\
\hline
\end{tabular}


Table 4 (continued)

\begin{tabular}{|c|c|c|c|c|c|c|c|c|c|}
\hline \multirow[t]{2}{*}{ Regions } & \multicolumn{3}{|l|}{ CI } & \multicolumn{3}{|l|}{ HDI } & \multicolumn{3}{|c|}{ Per capita GDP } \\
\hline & 1991 & 2001 & 2011 & 1991 & 2001 & 2011 & 1991 & 2001 & 2011 \\
\hline Lesvos & 7 & 9 & 19 & 29 & 16 & 11 & 38 & 31 & 26 \\
\hline Samos & 12 & 13 & 23 & 27 & 18 & 8 & 50 & 28 & 13 \\
\hline Chios & 4 & 5 & 11 & 28 & 10 & 3 & 22 & 11 & 21 \\
\hline Dodekanisos & 37 & 43 & 40 & 6 & 32 & 7 & 15 & 6 & 8 \\
\hline Kyklades & 5 & 15 & 37 & 9 & 13 & 2 & 2 & 3 & 1 \\
\hline Irakleio & 18 & 8 & 13 & 11 & 5 & 17 & 32 & 8 & 17 \\
\hline Lasithi & 36 & 27 & 22 & 3 & 17 & 6 & 6 & 9 & 10 \\
\hline Rethymno & 15 & 20 & 20 & 2 & 15 & 9 & 5 & 14 & 20 \\
\hline Chania & 16 & 11 & 10 & 7 & 7 & 5 & 25 & 20 & 11 \\
\hline
\end{tabular}

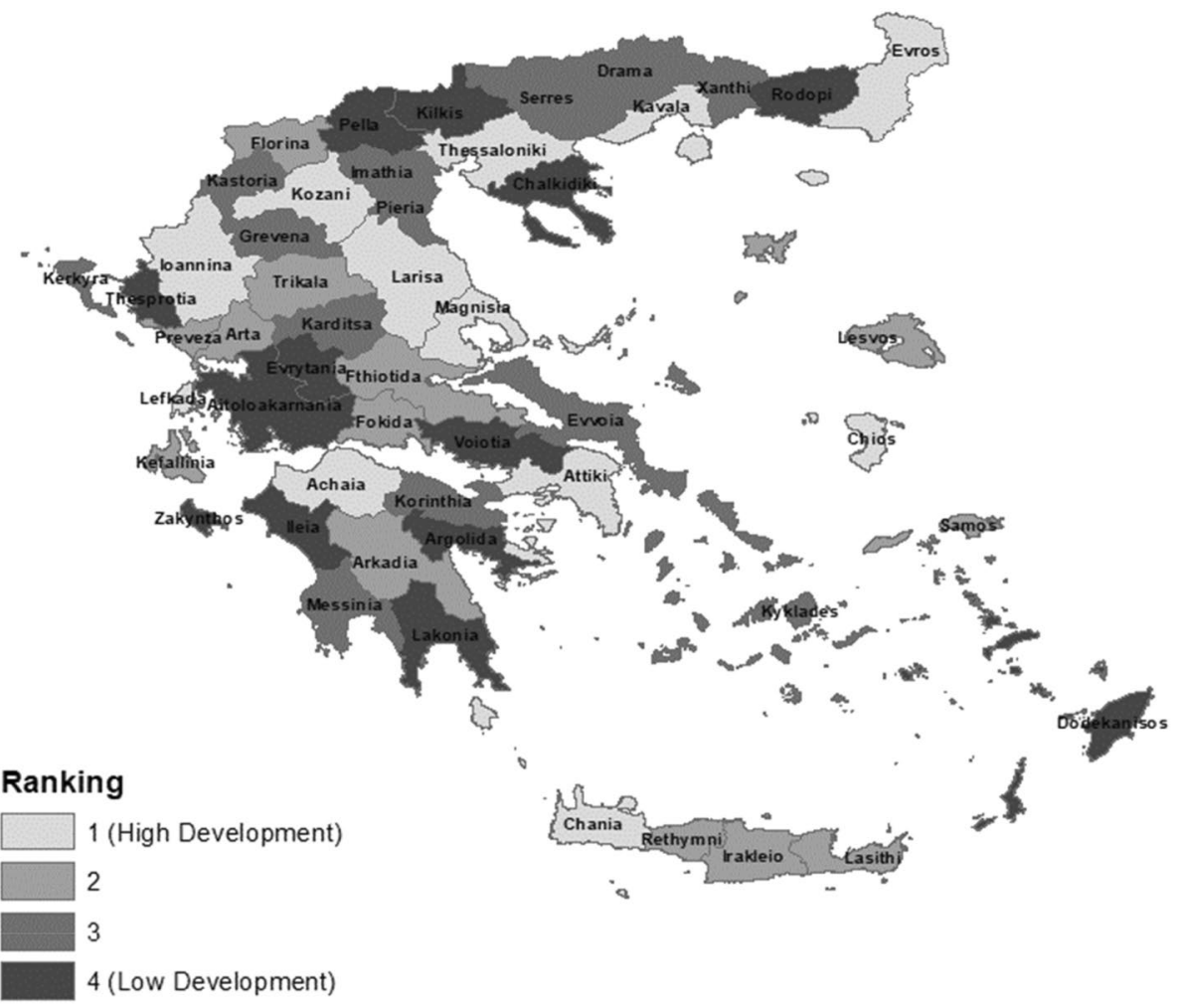

Fig. 3 Regional rankings of CI in quantiles in Greece, NUTS 3, 2011. Source: Authors calculations 
23rd, Zakynthos occupies the 19th and Voiotia occupies the 3rd position in the ranking of the HDI. From the above analysis, it is evident, once again, that there is not a strong correlation of rankings between the $\mathrm{CI}$ and the two alternative indicators; the rankings are dissimilar in several cases.

By comparing the CI diachronically, some important changes can be seen. For instance, Arta and Kozani presented one of the most remarkable improvements in terms of ranking. Arta gained 17 positions recording improvements in all sub-indicators except Health while Kozani gained 16 positions recording improvements in all sub-indicators except Health and Gender. The improvement of Kozani took place in the second period of analysis (i.e., 2001-2011). Other regions that gained several positions between 1991 and 2011 are Lasithi (+ 14 positions), Fokida (+11 positions), Trikala (+10 positions), Lefkada (+9 positions), Karditsa and Evros (+7 positions). On the other hand, many regions deteriorated their positions; these are, inter alia, Cyclades ( -32 positions), Preveza ( -13 positions), Lesvos ( -12 positions), Kerkyra, Voiotia and Samos (-11 positions) as well as Aitoloakarnania ( -9 positions).

\subsection{Sensitivity analysis}

As mentioned above, a CI involves subjective judgments and assumptions that might be potential sources of methodological problems and uncertainty affecting the quality and reliability of the index. For this reason, the application of sensitivity analysis is an essential ingredient in validating an index (OECD 2008). A series of sensitivity tests was performed in this study to assess the robustness of the rankings of the CI. More specifically, as far as normalisation is concerned, the z-score approach, which normalises data with fixed mean and standard deviation but different ranges, is also used. Using this method, indicators are standardised with a mean of zero and a standard deviation of one. To explore the robustness in terms of inclusion and exclusion of one dimension at a time, the CI was estimated eight times, once by including all of its dimensions, and then by excluding one dimension at a time. Finally, to examine the robustness of our results in the presence of other critical dimensions, ${ }^{10}$ we also include variables related to information technology and research and development (R\&D) as well as to the environment. Data for these dimensions of development are available only for 2011 and include: (1) the percentage of people with internet access (2) Research and Development (R\&D) expenditures (only at NUTS 2 level) and recycling rate i.e. the percentage of people that recycle. ${ }^{11}$

The general conclusion derived from the sensitivity analysis is that the rankings are robust and internally consistent with all alternative approaches. No significant differences arise among the different techniques; variability is a bit higher for the regions placed in the middle position of the array without changing, however, the general findings of this study.

\footnotetext{
10 The author thanks one of the referees for this suggestion.

11 The data source for the variables of Internet access and recycling rate were the census data (of 2011) provided by the Hellenic Statistical Authority (EL.STAT.). The R\&D expenditures data were obtained by the National Documentation Center.
} 


\section{Concluding remarks and policy implications}

There has been a growing consensus in recent years that development is a multidimensional concept that embodies the enhancement of several aspects of human life and, as a result, it is too complex to be captured by single indices. Composite Indicators have increasingly been recognised as useful tools in the measurement of this concept. In the absence of rigorous empirical studies in Greece, the study assessed and revealed the developmental transformations of the regional economies at NUTS 2 and 3 levels in the period 1991-2011, using the human development and capability approach as a benchmark. To estimate weights and address spatial heterogeneity, a recently developed technique, the spatial robust Benefit of the Doubt, was used.

Overall, the results showed that the more urbanised regions of the country, hosting significant cities, with a higher degree of economic openness, connectivity and productive participation of the tertiary sector (especially in the financial and insurance activities and real estate) present higher rankings concerning the CI. Interestingly, these were the regions that were more affected by the crisis in the period 2009-2015 (Artelaris 2017). On the other hand, the less urbanised regions of the country, border regions, and regions with the productive elements of agriculture and labour-intensive industry being more evident, present lower rankings. Moreover, by comparing the rankings of the CI with the rankings of two other popular indicators, that is, HDI and per capita GDP, major differences (especially in the case of per capita GDP) are evident among regions; for instance, several highly developed regions in terms of per capita GDP appear to be less developed regarding the CI and vice versa. Finally, it is worth noting that there are some significant differences in the regional rankings of our CI with the rankings obtained by previous similar studies, likely due to capturing a different perspective of development and a different weighting scheme.

The need for a sound regional analysis is strongly associated with public policy. The measurement and monitoring of regional development have been one of the main governmental priorities in recent years in several countries advancing towards more targeted public policy interventions. This is more important now than ever for the EU countries, as the European Cohesion Policy will be linked, in the new programming period (2021-2027), even more strongly to the place-based narrative by increasingly emphasising locally-led development strategies (Artelaris and Mavrommatis 2020). However, CIs should never be seen as a goal per se but rather as a starting point for more in-depth discussion among academia and public policymakers (Hoskins and Mascherini 2009; Artelaris 2017). In this regard, the findings of the study can be used by policymakers as a way to better understand and improve the regional development process. On the one hand, they can be used as guiding lights in the process and determination of policymaking, and on the other, as tools for the evaluation of performance and effectiveness of the adopted regional (and other) policies.

\section{References}

Alkire, S.: Human development: definitions critiques, and related concepts. SSRN Electron. J. (2010). https://doi.org/10.2139/ssrn.1815263

Anand, P., Hunter, G., Smith, R.: Capabilities and well-being: evidence based on the Sen-Nussbaum approach to welfare. Soc. Indic. Res. 74(1), 9-55 (2005)

Artelaris, P.: Geographies of crisis in Greece: a social well-being approach. Geoforum 84, 59-69 (2017) 
Artelaris, P.: Regional economic growth and inequality in Greece. Reg. Sci. Policy Pract. 13(1), 141-158 (2021)

Artelaris, P., Mavrommatis, G.: Territorial cohesion as a policy narrative: from economic competitiveness to 'smart' growth and beyond. Soc. Incl. 8(4), 208-217 (2020)

Artelaris, P., Tsirbas, Y.: Anti-austerity voting in an era of economic crisis: regional evidence from the 2015 referendum in Greece. Environ. Plan. C 36(4), 589-608 (2018)

Barrington-Leigh, C., Escande, A.: Measuring progress and well-being: a comparative review of indicators. Soc. Indic. Res. 135, 893-925 (2017)

Boarini, R., D'Ercole, M.: Going beyond GDP: an OECD perspective. Fisc. Stud. 34, 289-314 (2013)

Booysen, F.: An overview and evaluation of composite indices of development. Soc. Indic. Res. 59, 115151 (2002)

Burchi, F., Gnesi, C.: A review of the literature on well-being in Italy: a human development perspective. Forum Soc. Econo. 45(2-3), 170-192 (2015)

Calcagnini, G., Perugini, F.: A well-being indicator for the Italian provinces. Soc. Indic. Res. 142, 149-177 (2019)

Cartone, A., Panzera, D.: Deprivation at local level: practical problems and policy implications for the province of Milan. Reg Sci Policy Pract. 13, 43-61 (2020)

Cartone, A., Postiglione, P.: Principal component analysis for geographical data: the role of spatial effects in the definition of composite indicators. Spat. Econ. Anal. (2020). https://doi.org/10.1080/17421772. 2020.1775876

Casolani, N., Cartone, A., Postiglione, P., Liberatore, L.: Climate variability in agriculture and crop water requirement: spatial analysis of Italian provinces. J. Clean. Prod. 262, 121331 (2020)

Cherchye, L., Moesen, W., Rogge, N., van Puyenbroeck, T.: An introduction to 'benefit of the doubt' composite indicators. Soc. Indic. Res. 82, 111-145 (2007)

Claassen, R.: An agency-based capability theory of justice. Eur. J. Philo. 24(3), 1279-1304 (2016)

Çolak, M., Ege, A.: An assessment of EU 2020 strategy: Too far to reach? Soc. Indic. Res. 110(2), 659-680 (2013)

Cummins, R.A.: The domains of life satisfaction: an attempt to order chaos. Soc. Indic. Res. 38(3), 303-328 (1996)

Dasgupta, P.: Valuation and evaluation: measuring the quality of life and evaluating policy, in background paper prepared for the World Bank's annual World Development Report 2000. https://sticerd.lse.ac.uk/ dps/de/dedps22.pdf (2000)

Decancq, K., Lugo, M.A.: Weights in multidimensional indices of wellbeing: an overview. Economet. Rev. 32(1), 7-34 (2013)

Di Berardino, C., Mauro, G., Quaglione, D., Alessandro, S.: Industrial districts and socio-economic wellbeing: an investigation on the italian provinces disparities. Soc. Indic. Res. 129(1), 337-363 (2016)

Dialga, I., Giang, H.: Highlighting methodological limitations in the steps of composite indicators construction. Soc. Indic. Res. 131, 441-465 (2017)

Doyal, L., Gough, I.: Need satisfaction as a measure of human welfare, in W. Blass and J. Foster (eds), Mixed Economies in Europe (London: Edward Elgar) (1993)

Dreze, J., Sen, A.K.: India: Development and Participation. Oxford University Press, Oxford (2002)

Dunford, M.: Growth, inequality and cohesion: a comment on the Sapir Report. Reg. Stud. 39, 972-978 (2005)

Durand, M.: The OECD better life initiative: How's life? and the measurement of well-being. Rev. Income Wealth 61(1), 4-17 (2015)

Ferrara, R., Nisticò, R.: Regional well-being indicators and dispersion from a multidimensional perspective: evidence from Italy. Ann. Reg. Sci. 55, 373-420 (2015)

Frediani, A., Boni, A., Gasper, D.: Approaching development projects from a human development and capability perspective. J. Human Dev. Capab. 15(1), 1-12 (2014)

Freudenberg, M.: Composite indicators of country performance: A critical assessment, OECD Science, Technology and Industry Working Papers, 2003/16, OECD Publishing (2003). https://doi.org/10.1787/ 405566708255

Fusco, E., Vidoli, F., Sahoo, B.K.: Spatial heterogeneity in composite indicator: a methodological proposal. Omega 77, 1-14 (2018)

Galbraith, J.K.: The Affluent Society. Houghton Mifflin Company, Boston (1958)

Goletsis, Y., Chletsos, M.: Measurement of development and regional disparities in Greek Periphery: a multivariate approach. Socioecon. Plann. Sci. 45, 174-183 (2011)

Greco, S., Ishizaka, A., Tasiou, M., Torrisi, G.: On the methodological framework of composite indices: a review of the issues of weighting. Aggreg. Robust. Soc. Indic. Res. 141, 61-94 (2019) 
Grisez, G., Boyle, J., Finnis, J.: Practical principles, moral truth and ultimate ends. Am. J. Jurisprud. 32, 99-151 (1987)

Grupp, H., Schubert, T.: Review and new evidence on composite innovation indicators for evaluating national performance. Res. Policy 39(1), 67-78 (2010)

Hagerty, M.R., Cummins, R.A., Ferriss, A.L., Land, K., Michalos, A.C., Peterson, M., Sharpe, A., Sirgy, J., Vogel, J.: Quality of life indexes for national policy: review and agenda for research. Soc. Indic. Res. 55, 1-96 (2001)

Hoskins, B., Mascherini, M.: Citizenship through the development of a composite indicator. Soc. Indic. Res. 90, 459-488 (2009)

Hudson, R.: Regions and regional uneven development forever? Some reflective comments upon theory and practice. Reg. Stud. 41(9), 1149-1160 (2007)

Ivaldi, E., Bonatti, G., Soliani, R.: An indicator for the measurement of political participation: the case of Italy. Soc. Indic. Res. 132(2), 605-620 (2017)

Krishnan, V.: Development of a multidimensional living conditions index (LCI). Soc. Indic. Res. 120(2), 455-481 (2015)

Kuc-Czarnecka, M., Lo, P.S., Saltelli, A.: Quantitative storytelling in the making of a composite indicator. Soc. Indic. Res. 149, 775-802 (2020)

Kuznets, S.: How to judge quality. New Republic, 20 October p. 29 (1962)

Liargovas, P., Fotopoulos, G.: Socioeconomic indicators for analyzing convergence: the case of Greece: 1960-2004. Soc. Indic. Res. 93, 315-330 (2009)

Marchante, A.J., Ortega, B., Sánchez, J.: The evolution of well-being in Spain (1980-2001): a regional analysis. Soc. Indic. Res. 76, 283-316 (2006)

McGillivray, M.: Human well-being: Issues concept and measurement. In: McGillivray, M. (ed.) Human Well-being Concept and measurement, pp. 1-22. Palgrave Macmillan, Basingstoke and New York (2007)

Munda, G.: Beyond GDP: an overview of measurement issues in redefining 'wealth'. J. Econo. Surv. 29(3), 403-422 (2015)

Murias, P., Novello, S., Martínez-Roget, F.: The regions of economic well-being in Italy and Spain. Reg. Stud. 46(6), 793-816 (2012)

Murias, P., Novello, S., Martínez-Roget, F.: A malmquist-based approach to change in local economic well-being. Reg. Stud. 50(8), 1273-1289 (2016)

Narayan, D., Chambers, R., Shah, M.K., Petesch, P.: Voices of the Poor: Crying out for Change. Oxford University Press for the World Bank, New York (2000)

Nordhaus, D., Tobin, J.: Is growth obsolete? In: Moss, Milton (ed.) The Measurement of Economic and Social Performance, Studies in Income and Wealth, vol. 38. National Bureau of Economic Research, New York (1973)

Nussbaum, M.C.: Women and Human Development: The Capabilities Approach. Cambridge University Press, Cambridge (2000)

Nussbaum, M.: Creating Capabilities: The Human Development Approach. Harvard University Press (2011)

OECD (2007), Istanbul declaration, http://www.oecd.org/dataoecd/14/46/38883774.pdf.

OECD: Handbook on Constructing Composite Indicators: Methodology and User Guide. OECD, Paris (2008)

OECD: How's life? OECD, Measuring well-being, Paris (2011)

OECD (2013), How's life? 2013. Measuring well-being, OECD Publishing. http:www.oecd.org/measu ringprogress

OECD: How's Life? 2015: measuring Well-being. OECD Publ. Paris (2015). https://doi.org/10.1787/ how_life-2015-en

OECD (2019), Territorial Review of Greece - Preliminary Findings, Press Conference remarks, 19 March 2019 - Athens, Greece, http://www.oecd.org/greece/territorial-review-of-greece-preli minary-findings-greece-march-2019.htm

Oţoiu, A., Grădinaru, G.: Proposing a composite environmental index to account for the actual state and changes in environmental dimensions, as a critique to EPI. Ecol. Ind. 93, 1209-1221 (2018)

Papadaskalopoulos, A., Christofakis, M.: Spatial cohesion in Greece: The impact of GDP revision in the measurement of spatial inequalities in Greece and policy dimensions. Soc. Cohes. Dev. 3(1), 45-54 (2008)

Papalia, R., Ciavolino, E.: Developing a composite index by using spatial latent modelling based on information theoretic estimation. Qual Quant 49(3), 989-997 (2015)

Perrons, D.: Regional performance and inequality: linking economic and social development through a capabilities approach. Camb. J. Reg. Econ. Soc. 5, 15-20 (2012) 
Petrakos, G., Artelaris, P.: Regional Inequalities in Greece. In: Coccosis, H., Psycharis, Y. (eds.) (2008) Regional Analysis and Policy, pp. 121-139. Physica-Verlag HD, The Greek experience (2008)

Petrakos, G., Psycharis, Y.: Regional Development in Greece. Kritiki, Athens (2016).. ((in Greek))

Pike, A., Rodríguez-Pose, A., Tomaney, J.: What kind of local and regional development and for whom? Reg. Stud. 41(9), 1253-1269 (2007)

Raworth, K.,, Stewart D.: Critiques of the human development index: A review, In S. Fukuda-Parr \& A. K. Shiva Kumar (Eds.), Readings in human development: Concepts, measures and policies for a development paradigm. Oxford University Press, United States, pp 164-176 (2005)

Reig-Martınez, E.: Social and economic wellbeing in Europe and the Mediterranean basin: building an enlarged human development indicator. Soc. Indic. Res. 111, 527-547 (2013)

Saisana, M., Saltelli, A.: Expert panel opinion and global sensitivity analysis for composite indicators. Comput. Sci. Eng. 62, 251-275 (2008)

Saisana, M., Tarantola, S.: State-of-the-art Report on Current Methodologies and Practices for Composite Indicator Development, EUR 20408 EN, European Commission - Joint Research Centre. http://cites eerx.ist.psu.edu/viewdoc/download?doi=10.1.1.402.5612\&rep=rep1\&type=pdf (2002)

Saltelli, A: Composite indicators between analysis and advocacy. Soc. Indic. Res. 81(1), 65-77 (2007)

Samuelson, P.A.: The evaluation of social income: capital formation and wealth. In: Lutz, F., Hague, D. (eds.) The Theory of Capital, pp. 32-57. St. Martin's Press, New York (1961)

Sarra, A., Nissi, E.: A spatial composite indicator for human and ecosystem well-being in the Italian urban areas. Soc. Indic. Res. 148, 353-377 (2019)

Schwartz, S.H.: Are there Universal aspects in the structure and contents of human values? J. Soc. Issues 50(4), 19-45 (1994)

Sen, A.K.: Choice. Basil Blackwell Welfare and Measurement, Oxford (1982)

Sen, A.K.: Commodities and Capabilities. Cambridge University Press, Cambridge (1985)

Sen, A.K.: Capability and Well-being. In: Nussbaum, M., Sen, A. (eds.) The Quality of Life, pp. 30-53. Clarendon Press for UNU-WIDER, Oxford (1993)

Sen, A.: Inequality, unemployment and contemporary Europe. Int. Labour Rev. 138, 155-171 (1997)

Sen, A.: Development as Freedom. Oxford University Press, Oxford (1998)

Sen, A.: Assessing Human Development. Human Development Report 1999. Oxford UniversityPress, New Delhi (1999)

Sen, A.: Capabilities, lists, and public reason: continuing the conversation. Fem. Econ. 10(3), 77-80 (2004)

Silva, R., Ferreira-Lopes, A.: A regional development index for Portugal. Soc. Indic. Res. 118, 1055-1085 (2014)

Stiglitz J., Sen, A., Fitoussi, J.-P.: Report by the commission on the measurement of economic performance and social progress, Paris, www.stiglitz-sen-fitoussi.fr/documents/rapport_anglais.pdf (2009)

Strezov, V.J., Evans, A., Evans, T.: Assessment of the economic, social and environmental dimensions of the indicators for sustainable development. Sustain. Dev. 25, 242-253 (2017)

United Nations Development Programme (UNDP): Human Development Report 1990. Oxford University Press for UNDP, New York (1990)

Vidoli F. and Fusco E. (2019), Compind: Composite indicators functions. R package version 2.1. Retrieved April 2, 2021, from https://rdocumentation.org/packages/Compind/versions/2.1

Walheer, B.: Disentangling heterogeneity gaps and pure performance differences in composite indexes over time: the case of the Europe 2020 strategy. Soc. Indic. Res. 143, 25-45 (2019)

WEF: The Global Gender Gap Report 2017. World Economic Forum, Geneva (2017)

Wüst, K., Volkert, J.: Childhood and capability deprivation in Germany: a quantitative analysis using German Socio-economic panel data. Soc. Indic. Res. 106, 439-469 (2012)

Publisher's Note Springer Nature remains neutral with regard to jurisdictional claims in published maps and institutional affiliations. 